\title{
INTRODUÇÃO À FILOSOFIA EM TEMPOS DE ASCENSÃO FASCISTA: UM RELATO DE EXPERIÊNCIA
}

\author{
INTRODUCCIÓN A LA FILOSOFIA EN TIEMPOS DE ASCENSIÓN FASCISTA: UN \\ RELATO DE EXPERIENCIA
}

Rafael da Silva Cortes'

\begin{abstract}
Resumo: Esse relato de experiência visa expor a metodologia e o referencial teórico das aulas de "Introdução à filosofia", ministradas em turmas do Ensino Médio do Colégio de Aplicação da Universidade Federal do Rio Grande do Sul. O objetivo das aulas foi promover a compreensão dos estudantes de que a Filosofia é uma atividade reflexiva autônoma, portanto, antagônica a preconceitos e ao cerceamento do pensamento.
\end{abstract}

Palavras-chave: introdução à filosofia; fascismo; banalidade do mal; autonomia; Aufklärung.

\begin{abstract}
Resumen: Este relato de experiencia busca exponer la metodología y el referencial teórico de las clases de "Introducción a la filosofía", impartidas en grupos de la Enseñanza Secundaria del Colégio de Aplicação de la Universidad Federal de Río Grande do Sul. El objetivo de las clases ha sido el de promover la comprensión por parte de los estudiantes de que la filosofía es una actividad reflexiva autónoma y, por lo tanto, antagónica a prejuicios y a la cohibición del pensamiento.
\end{abstract}

Palabras clave: introducción a la filosofía; fascismo; banalización del mal; autonomía; Aufklärung.

\section{INTRODUÇÃO}

Com o advento da internet e das redes sociais temos sido colocados constantemente diante de inúmeras manifestações de ódio, desrespeito aos direitos humanos, ataques verbais e físicos contras minorias historicamente desfavorecidas no tocante a garantia de seus direitos (negros, LGBTs, mulheres, povos originários, etc), bem como defesas públicas à tortura, aos torturadores e ao extermínio de comunidades pobres. Particular, mas não exclusivamente no Brasil, há pouco mais de dois anos temos visto o recrudescimento de ataques à ciência, às artes, às universidades, às escolas, aos (às) professores (as), ou seja, a toda categoria que se dispõe a formular um discurso contra-hegemônico e a pensar sobre as raízes e as soluções dos problemas sociais. Nesse sentido, 
como professor de Filosofia da educação básica pública, entendo que se constitui em tarefa central desse componente curricular, mas não exclusivamente dele, ensinar aos jovens a importância do conhecimento, do questionamento, da dúvida, do debate e do apresso à verdade, enfim, do pensar como mecanismo de enfrentamento de posturas dogmáticas e totalitárias que desprezam a ciência, a arte e a reflexão.

Esse ensaio divide-se em quatro partes: a primeira é destinada a apresentação geral do contexto sociopolítico nacional sob o qual as atividades de ensino aqui apresentadas foram desenvolvidas. Essa etapa de contextualização se faz relevante porque, conforme argumento nesse trabalho, as manifestações antidemocráticas e fascistas de certos setores da sociedade civil ganharam corpo, tornando-se cada vez mais frequentes e explícitas, a partir do engendramento de certas arbitrariedades no âmbito da política nacional; a segunda parte desse relato se dedica a apresentar brevemente algumas características do Colégio de Aplicação da Universidade Federal do Rio Grande do Sul - doravante CAP/UFRGS -, onde as aulas aqui relatadas foram desenvolvidas; na terceira parte, concentro-me no propósito principal desse trabalho, qual seja, relatar as experiências das aulas de "Introdução à Filosofia", ministradas para turmas de primeiro ano do Ensino Médio, bem como a metodologia e o referencial bibliográfico empregados; a quarta e última parte desse relato reservo para as considerações finais.

\section{POLÍTICA, (DES)INFORMAÇÃO E REDES SOCIAIS: O FASCISMO EMERGE E ESCOLHE A ESCOLA COMO ALVO.}

Em palestra proferida na ocasião do recebimento do título de doutor honoris causa em 10 de junho de 2015 na Universidade de Turim na Itália, o filósofo Umberto Eco afirmou que, mais do que nunca, as redes sociais deram voz a uma legião de imbecis². Não consiste em desafio a constatação da veracidade da afirmação de Eco, pois o teor dos incontáveis comentários de usuários das redes sociais, redigidos em reportagens de jornais online são suficientes para comprovar a afirmação do filósofo italiano. Comentários que, diga-se de passagem, são capazes de abalar até mesmo a crença do mais forte otimista no progresso da humanidade. Evidentemente, as salas de aula - sejam da educação básica, sejam do ensino superior - não estão imunes à mentalidade explicitada por comentários daquele tipo. Diante disso, como professor de Filosofia para adolescentes, entendo como sendo de fundamental importância o fomento à reflexão filosófica através de seus métodos, história e especificidades na certeza de que tais conhecimentos podem ser decisivos no enfrentamento de posturas dogmáticas, antidemocráticas e fascistas ${ }^{3}$.

No Brasil, essa legião de imbecis é composta, em grande parte, pela parcela da população historicamente privilegiada, contrária às políticas públicas de distribuição de renda e às políticas

2 Conforme disponível em: < http://www.lastampa.it/2015/06/10/cultura/eco-con-i-parola-a-legioni-di-imbecilli-XJrvezBN4XOoyo0h98EfiJ/pagina.html > Acesso em: 09 outubro de 2018. A palavra "imbecil" deriva do latim imbecille que significa "sem bastão", "sem bengala". Evidentemente que não se trata da ferramenta geralmente utilizadas por idosos ou portadores de deficiência para apoio ao caminhar. Trata-se, ao contrário, de seu sentido metafórico e se refere àquelas pessoas que precisam de outro tipo de apoio, devido à fragilidade de espírito, de intelecto. Em nosso idioma, a palavra imbecil tem o mesmo sentido que as palavras idiota, tolo, néscio. A palavra idiota deriva do grego ídion, que significa particular, privado. Ela se opõe, no contexto político da Grécia Antiga, a koinón que significa o comum, públiCO (SPINELLI, 2017, p. 24). Ainda segundo o autor, "Por princípio, o idiótes não comportava uma conotação negativa: simplesmente designava o particular em termos do que lhe é próprio, que lhe pertence e que, evidentemente, caberia preservar, mas não em detrimento do todo. Daí que o conceito de idiótes paulatinamente agregou um sentido negativo, à medida que o particular passou a dar mais importância a seus interesses privados que aos interesses públicos" (SPINELLI, 2017, p. 24. Grifos do autor). Em entrevista a Deutsche Welle Brasil, o professor de filosofia Mario Sergio Cortella segue na esteira da afirmação de Eco acerca da imbecilidade promovida pelas redes sociais e nas constantes manifestações de ódio disponível na web em: < https://www.dw.com/pt-br/m\%C3\%ADdias-sociais-favoreceram-a-imbecilidade/a-41567902 >, acesso em: 07 de abril de 2019. Dias da Silva (2019), em artigo publicado recentemente na página eletrônica Outras Mídias, analisa a relação entre o cenário político atual no Brasil e as manifestações de ódio nas redes sociais promovida pelos idiotas ou imbecis (denominados por ele de "indiferentes") sob a ótica de Hannah Arendt, conforme disponível em: < https://outraspalavras.net/outrasmidias/bolsonaro-arendt-e-a-ignorancia-esmagadora-dos-indiferentes/? fbclid=IWAR 1 KREIPhyicve0n1EpMFMzd2RSD5dGnejnsqaY-15XUJ3CN13CWEEsjIXU >.

3 Em palestra proferida em 1995 nos EUA, ECo (2018, p. 44) nos revelara as características típicas do chamado "Ur-fascismo" ou "fascismo eterno" as quais, mesmo passados mais de 20 anos, ainda hoje são bastante instrutivas e atuais. 
de ações afirmativas engendradas por governos recentes, do início no século XXI. É curioso observar que essa mesma parcela da população se considera capaz de opinar sobre justiça, arte, educação e política como se dominasse os conhecimentos envolvidos nessas áreas quando, na verdade, seus juízos são recheados de informações do nível de senso comum e preconceitos, afinal aquelas áreas de conhecimento humano muitas vezes não despertam o interesse dessa parcela da população. Dito com outras palavras, a população brasileira que se compraz em questionar a legitimidade de exposições artísticas, que concorda com linchamentos públicos como forma de punição, que é contrária às discussões sobre gênero nas escolas é, geralmente, a mesma que pouco ou nada lê e estuda sobre arte, justiça e gênero.

No caso específico dos juízos sobre justiça desses(as) cidadãos(ãs), não raras vezes percebemos manifestações que clamam por um rigorismo jurídico, que na verdade brotam do mais puro e íntimo ódio contra pequenos furtos e roubos geralmente praticados por jovens pobres, negros e periféricos. Paradoxalmente, essas mesmas pessoas são mais condescendentes em relação a crimes cujas consequências sociais são muito mais graves, como os perpetrados pelo "colarinho branco": tráfico de armas e drogas, a título de exemplo. O mesmo senso de justiça seletivo dessa parcela da população se observa em relação aos casos de corrupção no país, diária e seletivamente, é preciso dizer, revelados pelos mesmos meios de comunicação frequentemente envolvidos com crimes de sonegação fiscal, por exemplo. Trata-se daquela parcela da população denominada por Souza (2019) de "elite do atraso".

Todavia, esse comportamento não é recente, tampouco exclusivo da classe média brasileira. Ao contrário, não é demasiado lembrar que esses mesmos "cidadãos de bem" apoiaram, e muitos continuam apoiando, os cruéis e corruptos governos militares que se espalharam pela América Latina com o apoio dos EUA desde a década de 1960. Para não exemplificar apenas com aquilo que nos é mais próximo, também podemos lembrar de outras populações mundialmente conhecidas que engendraram comportamento semelhante e até mesmo mais grave às ideias defendidas por essa parcela da população brasileira. Refiro-me aqui ao apoio e a condescendência de parcela significativa da população alemã com a ascensão e ações levadas a cabo pelo partido nazista antes e durante a II Guerra Mundial. Ou ainda, conforme ocorre atualmente em diferentes países europeus, o retorno aos palcos políticos de defensores de ideais de extrema direita com representação eleitoral cada vez mais significativa.

Ao relembrar dos acontecimentos do passado, mais especificamente dos regimes totalitários europeus e ditatoriais na América Latina, somos levados a refletir sobre as causas de tamanha crueldade engendrada contra a humanidade bem como os discursos que sustentaram tais atrocidades. Afinal, não aprendemos nada com os episódios de maldade extrema e explícita do passado? Quais as causas de tamanha maldade? Diferentemente do que geralmente aprendemos através das religiões, o mal não parece ser algo supra-humano ou demoníaco. Ao contrário, o mal parece muito mais próximo do nosso alcance do que geralmente imaginamos e as redes sociais apenas o teriam tornado explícito aos nossos olhos diariamente, conforme a constatação de Umberto Eco aponta.

A propósito, Hannah Arendt (1999) demonstra através de suas reflexões sobre o mal e suas consequências ético-políticas perpetradas por regimes totalitários, que os genocídios não foram e não são atos realizados por demônios, nem por rebeldes e insubordinados. Através de seus estudos e reflexões sobre o mal, ela nos apresenta uma verdade que talvez apenas fingíamos desconhecer: que o mal pode surgir daquelas pessoas que consideramos como as mais comuns. Afinal, os maiores crimes contra a humanidade cometidos no século XX foram realizados por criminosos que estavam muito bem integrados ao sistema e que realizavam suas funções especializadas com competência, tais como os praticados pelo oficial nazista Adolf Eichmann, personagem principal da análise da autora em seu famoso livro "Eichmann em Jerusalém: um relato sobre a banalidade do mal" (1963), o qual serviu como fio condutor para as aulas de "Introdução à Filosofia" relatadas nesse trabalho. 


\section{CAP/UFRGS: CARACTERÍSTICAS E ESTRUTURA GERAL DA ESCOLA}

O CAP/UFRGS conta com um professor e uma professora de Filosofia. Em 2018, ano em que as aulas relatadas nesse trabalho foram desenvolvidas, o componente curricular Filosofia era ministrado nas seis turmas do ensino médio regular, sendo duas de primeiro, duas de segundo e duas de terceiro ano, e nas três turmas da EJA ensino médio, sendo uma turma de cada série. As duas turmas de primeiro ano do ensino médio regular eram compostas por trinta e cinco e trinta e três estudantes, com média de dezesseis anos de idade.

Cabe destacar três dados histórico-geográficos acerca do CAP/UFRGS: é uma instituição de sessenta e cinco anos de história; até o início dos anos 1990 localizava-se na área central da cidade de Porto Alegre/RS e no início da década de 1990 foi transferida para o Campus do Vale da Universidade Federal do Rio Grande do Sul, localizado na periferia da capital gaúcha, divisa com o município de Viamão; na mesma época da mudança de sede da escola foi instituído o sorteio como método de ingresso de novos estudantes, em substituição às provas públicas de seleção. A menção a tais dados sobre o CAP/UFRGS se faz importante, sobretudo os dois últimos (mudança de sede e de método de ingresso de estudantes), na medida em que são fundamentais para a determinação do perfil diverso - geográfico, histórico e econômico - dos estudantes não só do ensino médio, mas de toda a escola.

Outra característica relevante da escola a ser destacada é a autonomia didático-pedagógica dos professores. Isso significa que os professores do CAP/UFRGS decidem sobre o programa curricular e a metodologia de ensino a ser desenvolvida nos componentes curriculares - salvaguardando, obviamente, as determinações legais que regulam a educação básica do país. A propósito, não obstante o objetivo principal desse trabalho estar focado no relato das aulas de introdução à filosofia ministradas para as turmas de primeiro ano do ensino médio, é importante atentar para as recentes e graves propostas de mudanças legislativas em curso no país e que vão de encontro à referida autonomia didático-pedagógica de todos (as) os (as) professores (as) do país, sobretudo os (as) de escolas públicas. Refiro-me mais precisamente ao projeto "Escola sem partido" em análise no congresso4. Não tenho dúvidas de que a autonomia didático-pedagógica docente - acompanhada da garantia de direitos de carreira (aperfeiçoamento e planejamento), valorização salarial, infraestrutura adequada e qualificada - consiste em uma característica decisiva para a qualidade das formações pedagógicas dos (as) estudantes da educação básica e que, portanto, deve ser preservada e ampliada a todas as instituições públicas de ensino do país.

A última característica curricular do ensino médio regular do CAP/UFRGS que faço questão de destacar aqui é o fato de que todos os componentes curriculares dessa etapa da educação básica da escola têm encontros semanais com os estudantes de, ao menos, dois períodos de quarenta e cinco minutos. Esse também é o caso, portanto, do componente curricular Filosofia, mas também: Geografia, História, Sociologia, Teatro, Música, Artes, Português, etc.

\section{INTRODUÇÃO À FILOSOFIA EM TEMPOS DE ASCENSÃO FASCISTA:UMRELATO DE EXPERIÊNCIA DE AULAS EM TURMAS DO PRIMEIRO ANO DO ENSINO MÉDIO.}

Ante o acirramento e o teor das manifestações a respeito das motivações e das consequências geradas pelas mudanças políticas no país recentemente, manifestações também observadas em sala de aula, tornou-se notória a necessidade de motivar os estudantes de Filosofia

4 Conforme disponível em: < http://www2.camara.leg.br/camaranoticias/noticias/EDUCACAO-E-CULTURA/560313-DIVERGENCIAS-IMPEDEM-VOTACAO-DO-PARECER-SOBRE-A-\%E2\%80\%9CESCOLA-SEM-PARTIDO\%E2\%80\%9D.html > ACesSO em: 17 de setembro de 2018. 
à reflexão sobre noções e conceitos cuja a análise são fundamentais para a melhor compreensão do atual contexto político e social brasileiro, bem como sobre suas possíveis consequências.

Ao assumir a responsabilidade de apresentar a Filosofia às turmas de primeiro ano do ensino médio regular da escola, encarei essa situação como uma promissora oportunidade para revelar aos adolescentes dessas turmas uma propriedade fundamental, mas não a única, dessa área de conhecimento, a saber: a Filosofia como um exercício reflexivo sobre problemas e conceitos básicos com os quais nos deparamos frequente e diariamente, sobretudo em se tratando do período da adolescência. Sendo assim, elaborei um plano de ensino que denominei "Introdução à filosofia em tempos de ascensão fascista", cujo propósito foi caracterizar a Filosofia como uma área de investigação que produz conhecimentos mediante o exercício da reflexão, crítica/análise e elucidação de problemas e conceitos. Cabe salientar que o referido título atribuído ao módulo introdutório não era de conhecimento das turmas e que, além disso, foi estabelecido posteriormente ao início das aulas de introdução à Filosofia.

Vale destacar também que os problemas e conceitos sobre os quais nos debruçamos em nossos estudos de introdução à filosofia não são de uso exclusivo desse componente curricular. Ao contrário, tratam-se de conceitos utilizados cotidianamente pelas comunidades de fala, por assim dizer, nas quais os próprios estudantes estão inseridos ou com as quais temos algum tipo de contato frequente, seja através dos componentes curriculares da escola, das mídias, da internet e das redes sociais, por exemplo. Os problemas e conceitos mais analisados em aula foram: banalidade do mal, autonomia e esclarecimento (Aufklärung). Além disso, procurou-se enfatizar a distinção entre debate e discussão a fim de apontar que o primeiro representa um importante mecanismo de desenvolvimento da atividade filosófico-reflexiva na medida em que oportuniza o confronto de argumentos, perspectivas e teses a respeito de certo problema.

O módulo de "Introdução à filosofia", objeto de análise nesse relato, foi desenvolvido ao longo de catorze períodos de aula, sendo que dois desses períodos foram destinados à exibição do filme "Experimenter: the Stanley Milgram Story" (ALMEREYDA, 2015) que retrata alguns experimentos de psicologia social acerca da obediência e da autoridade desenvolvidos pelo psicólogo estadunidense Stanley Milgram a partir do início da década de 1960. Milgram, contrário à crença academicamente predominante daquele período, ratificou e aprofundou as conclusões de Hannah Arendt sobre a banalidade do mal e a "obediência cadavérica" (ARENDT, 1999, p. 152) ao demonstrar que o mal também poderia ser constatado em ações realizadas por cidadãos estadunidenses de classe média se essas pessoas fossem submetidas a certas condições em que deveriam seguir ordens, ainda que reconhecidamente imorais e fisicamente danosas.

Além da exibição do filme de Almereyda com o propósito de sensibilizar as turmas para a importância da temática, também utilizei outros três materiais didáticos para o desenvolvimento das aulas: passagens do livro "Eichmann em Jerusalém: um relato sobre a banalidade do mal" (1999) de Hannah Arendt, fragmentos da "Apologia de Sócrates" (1983) de Platão e o artigo "Resposta à pergunta: o que é esclarecimento?" (2011) de Immanuel Kant.

Conduzi a leitura dos textos nas turmas tendo como objetivos desenvolver, primeiro, as habilidades dos (as) estudantes de compreensão dos contextos histórico-culturais sob os quais a escrita de cada um dos referenciais bibliográficos estavam inseridos; segundo, a habilidade de compreensão sobre os propósitos dos autores ao se debruçarem sobre as temáticas abordadas nos textos; e terceiro, compreensão conceitual dos problemas filosóficos centrais. O alcance desses objetivos era de fundamental importância para o aperfeiçoamento (não desenvolvimento pleno, evidentemente) da competência analítico-comparativa do (as) estudantes, ou, dito com outras palavras, de suas capacidades de reconhecer nos acontecimentos histórico-culturais do passado características que pudessem auxiliá-los (as) na melhor compreensão do presente para, por conseguinte, serem capazes de se posicionar de forma argumentativa frente ao contexto político-social brasileiro atual. Por fim, esperava-se que, se atingidos aqueles objetivos, seria possível apontar para uma finalidade ainda mais importante: o desenvolvimento do potencial reflexivo 
autônomo dos (as) estudantes.

Conforme mencionado, o foco principal da leitura e análise do texto de Arendt foi o conceito de banalidade do mal. Com o intuito de atingir os objetivos descritos acima, iniciei a abordagem apresentando a filósofa, sua importância dentro da história da Filosofia, bem como o contexto histórico, político e cultural no qual sua obra estava inserida. Entendo como sendo uma etapa relevante, ainda que secundária, a contextualização histórica das temáticas e dos referenciais teóricos nos quais apoiamos nossa abordagem didático-pedagógica em Filosofia. Isso significa que, diferentemente do que algumas abordagens sobre o ensino de Filosofia na educação básica defendem, não compreendo como verdadeira a dicotomia entre ensinar Filosofia a partir de sua história ou ensinar Filosofia a partir de seus problemas. Ao contrário, compreendo como sendo uma falsa dicotomia e as aulas desse componente curricular no CAP/UFRGS confirmam essa compreensão. Ainda assim, cabe elucidar que denomino de secundária a contextualização histórica na medida em que serviu para que os (as) estudantes tivessem melhores condições de compreender a relevância da proposta de Arendt ao lançar mão do conceito de banalidade do mal, afinal, como sabemos, trata-se de um conceito elaborado pela autora a partir de seu testemunho das consequências desencadeadas pelos acontecimentos históricos e políticos europeus da primeira metade do século XX, mais precisamente a II Guerra Mundial. Portanto, parece inconteste que, ao menos em relação a determinadas temáticas curriculares, a contextualização histórica é decisiva para a melhor compreensão dos problemas e conceitos filosóficos envolvidos, desde que o foco didático do componente curricular não se concentre exclusivamente nessa perspectiva. Nesse caso, o conceito arendtiano de banalidade do mal.

Em ambas as turmas, o estudo, a análise e o debate sobre o conceito de banalidade do mal se desenvolveu mediante o uso de fragmentos dos capítulos II e VIII denominados, respectivamente, "O acusado" e "Deveres de um cidadão respeitador", do texto de Arendt (1999), bem como fragmentos do artigo de Souki5 (2013). O estudo do conceito arendtiano se desenvolveu ao longo de quatro períodos de aula. O interesse, o envolvimento e a compreensão pelas turmas acerca da temática abordada pela filósofa alemã se tornou evidente devido ao qualificado nível de envolvimento apresentado pelos (as) estudantes por meio de exercícios dissertativo-argumentativos, bem como pelas pertinentes participações orais observadas em sala de aula. Os (as) estudantes foram capazes de estabelecer consistentes relações e coerentes comparações entre o conceito de banalidade de mal e as constantes posturas repressivas engendradas por representantes do Estado brasileiro, nos mais diferentes níveis de manifestação de seu poder e força: nas manifestações de estudantes contra o aumento de passagens do transporte público e agressões sofridas por jovens cotidianamente em bairros e praças de cidades da região metropolitana de Porto Alegre.

Tomando como ponto de partida a análise feita por Hannah Arendt do julgamento de Adolf Eichmann, iniciado em 11 de abril de 1961 na Corte Distrital de Jerusalém (evento que marcou a vida pessoal e reflexiva da filósofa em virtude das declarações, do comportamento do oficial nazista e da repercussão de seu relato na comunidade judaica) desenvolvi com as turmas um estudo mais detalhado do trabalho da autora através de leituras comentadas dos fragmentos dos textos já mencionados. Arendt constatou que a opção por não refletir e questionar as ordens imorais que o oficial nazista recebia - "obediência cadavérica" segundo as palavras do próprio Eichmann, que resultou na ação de enviar milhões de pessoas para a morte nos campos de concentração - representa a abstenção pelo pensamento. O não pensar que, segundo consideração da autora, consiste na principal característica da banalidade do mal na medida em que as pessoas optam deliberadamente por essa perspectiva e assim, acabam por abrir mão dessa propriedade humana mais fundamental. Segundo ela, "Quanto mais se ouvia Eichmann, mais óbvio ficava que sua incapacidade de falar estava intimamente relacionada com sua incapacidade de pensar, ou seja, de pensar do ponto de vista de outra pessoa" (ARENDT, 1999, p. 62, grifos da

5 SOUKI, Nádia. "Três momentos do conceito de mal em Hannah Arendt". IN: SÔNIA, Maria Schiv; KUSKOSKI, Matheus Soares (orgs.). Hannah Arendt: pluralidade, mundo e política. Porto Alegre: Observatório Gráfico, 2013. 
autora).

A partir do estudo e reflexão sobre o conceito arendtiano de banalidade do mal, apresentei às turmas do primeiro ano do ensino médio do CAP/UFRGS um fragmento do diálogo platônico "Apologia de Sócrates" (PLATÃO, 1983). Através de nova leitura comentada, agora do texto platônico, a turma foi convidada a refletir sobre a justiça da acusação sofrida por Sócrates de ser responsável por corromper a juventude por instigá-la a refletir sobre a legitimidade das leis e dos deuses de Atenas. A essa acusação Sócrates contra-argumenta ao seu acusador, Meleto, que não ensina aos jovens nem a ninguém a se comportar dessa forma, como lemos no excerto a seguir:

[...] nunca quis ser mestre de ninguém. Se alguém, jovem ou velho, me desejar ouvir a falar ou me desejar ver a fazer o que me compete, nunca o recusei; [...] nunca prometi qualquer instrução a qualquer um deles, nem o ensinei. E se alguém disser que ouviu ou aprendeu alguma coisa comigo, enquanto os outros dizem que não, sabei que não está a dizer a verdade (PLATÃO, 1983, 33b).

A passagem acima nos possibilitou refletir sobre a verdadeira atividade desempenhada por Sócrates: o exercício da maiêutica (maieutike) e sua conexão com a acusação de ser corruptor da juventude grega. Como o trecho acima evidenciou, Sócrates não se considera mestre de sabedoria mas, isso sim, alguém que exerce uma atividade semelhante àquela desempenha pela sua mãe. Em vez de ajudar aos bebês virem à luz, Sócrates dizia ajudar aos jovens a parirem as ideias e conhecimentos que já gestavam em suas mentes (PLATÃO, 2001, p. 11). Para tanto, segundo o filósofo, é preciso exercitar sua capacidade reflexiva e questionadora. Ou ainda, dito com outras palavras, é preciso exercer a atividade filosófica.

Outra análise oportunizada pelo diálogo platônico foi em relação às atuais e cada vez mais constantes acusações oriundas de certos setores da sociedade brasileira, cujo alvo é a categoria docente. Guardadas as devidas proporções e as diferenças contextuais, a partir da reflexão originária dos próprios estudantes, foi possível traçar um paralelo entre a acusação dirigida à Sócrates (de ser corruptor da juventude ateniense) com as acusações que atualmente a categoria docente brasileira enfrenta, se tratando, sobretudo, dos professores de escolas públicas, os quais seriam responsáveis, assim como o filósofo ateniense, de corromper os (as) estudantes e, consequentemente, introduzir em suas mentes ideias e concepções de ideologias marxistas, de gênero, feministas, enfim, qualquer ideia contra-hegemônica. A identificação desse infeliz paralelo pelos (as) estudantes, por si só, serviu como importante indicador do qualificado e profundo envolvimento das turmas com o componente curricular Filosofia nesse módulo introdutório.

Cabe mencionar que a leitura orientada e o estudo do diálogo platônico foi precedida de uma apresentação histórico-cultural no qual o autor e Sócrates estavam inseridos, bem como sobre suas relevâncias para a história da filosofia com o intuito de contextualizar aos (às) estudantes das turmas de primeiro ano sobre a temática principal em causa e, consequentemente, contribuir para sua melhor compreensão e análise dos conceitos. Nesse sentido, da mesma forma que o estudo do conceito arendtiano de banalidade do mal, o estudo da "Apologia" também exigiu quatro períodos de aula em ambas as turmas.

Após o contato e o envolvimento com os dois referenciais bibliográficos supramencionados e o filme, o terceiro e último conceito analisado foi aquele que talvez seja o mais fundamental e decisivo para a compreensão do significado do exercício da atividade filosófica, a saber, o conceito de autonomia. Para tanto, disponibilizei às turmas o contato com outro fragmento de texto clássico da história da Filosofia: o artigo de Kant intitulado "Resposta a pergunta: o que é esclarecimento (Aufklärung)?". Após a contextualização do autor e de sua obra, iniciamos a lei- 
tura comentada e análise do texto. Concentramo-nos inicialmente nas duas primeiras frases do artigo, as quais são amplamente conhecidas pela comunidade filosófica devido à objetividade e a precisão conceitual que trazem consigo, mas também por muitos mal-entendidos gerados. Faço questão de reproduzi-las devido sua importância para o contexto não só das aulas lecionadas nas turmas objetos desse relato, mas também para a compreensão dos mais recentes acontecimentos políticos e sociais no país. Kant responde a pergunta que intitula seu artigo da seguinte maneira: "Esclarecimento é a saída do ser humano de sua menoridade, menoridade essa na qual ele se inseriu por sua própria culpa. Menoridade é a incapacidade de servir-se do seu próprio entendimento sem a condução de outrem" (KANT, 201 1, p. 23). Na esteira do conceito arendtiano de banalidade do mal estudado em aulas anteriores, e que é caracterizado pela autora como contendo fortes traços, por assim dizer, da escolha do agente racional por não refletir sobre seus atos e suas trágicas consequências, nos debruçamos no estudo da definição kantiana de "esclarecimento" (Aufklärung).

Através da passagem supracitada, Kant ratifica a importância filosófica da autonomia do sujeito para a saída de sua menoridade. Isso significa que ao se tornar um sujeito esclarecido, isto é, capaz de fazer uso de sua autonomia da vontade, nos tornamos capazes de questionar aquela "obediência cadavérica" identificada por Arednt como uma característica da banalidade do mal, oriunda do abandono da atividade reflexiva e crítica tipicamente humana. Mais do que isso, Kant alega que a menoridade intelectual tem como causa a "preguiça e a covardia" dos agentes, na medida em que optam pela menoridade e, entre outras coisas, obedecem de maneira indubitável ordens nitidamente imorais e injustas que podem afrontar a dignidade humana de indivíduos particulares e/ou de grupos inteiros.

Assim como nos estudos dos componentes textuais e conceituais anteriores do módulo introdutório de Filosofia, a análise do artigo de Kant também gerou significativo e qualificado envolvimento de ambas as turmas do primeiro ano do ensino médio regular do CAP/UFRGS, conforme pôde-se observar através das perguntas, comparações, objeções e colocações orais dos (as) estudantes, bem como de seus trabalhos dissertativo-argumentativos elaborados. Como exemplos da qualificada compreensão sobre o significado da atividade filosófica pelas turmas e da compreensão a respeito da relação entre os conceitos estudados e a própria Filosofia, apresento abaixo quatro trabalhos6 parciais da avaliação final do módulo de introdução à Filosofia, realizados pelos (as) estudantes. Conforme consta no enunciado7 da avaliação parcial, foi solicitado que eles (as) redigissem uma redação.

Trabalho 1:

\footnotetext{
6 As identificações dos (as) estudantes foram suprimidas para preservar suas identidades. Os (as) estudantes autorizaram a reprodução dos seus trabalhos nesse relato de experiência.

7 O enunciado do exercício era o seguinte: A partir dos conhecimentos adquiridos nas aulas de filosofia até o momento - debates, leituras e estudos - redija um texto (argumentativo dissertativo contendo introdução, desenvolvimento e conclusão) relacionando os conceitos de banalidade do mal, esclarecimento e filosofia. Como fio condutor temático do seu texto responda à pergunta: o que é filosofia?
} 
(1) que é felosolia?

Derirado de Grega, a palarra filasafua ssignifuca "amar a salvedoria". Filasolua se dá ao questionaments de questies saciais, culturas, suligio, sas e íticas. Chuestianse a rmods de pervar e a conruiriencia do ser tumano em saciedade.

Aquele que so rocuso a pensor, a questisives e upe

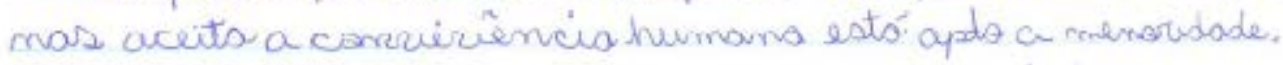
Amensaridade dufine a hasmem come incapary de facer usa

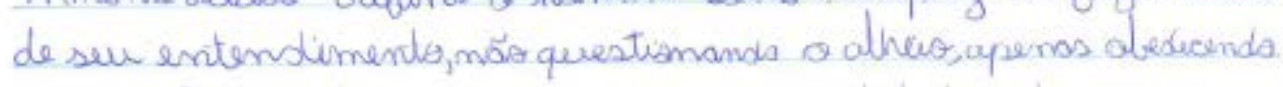
regras A corardia, a preguiso e a corroadidads sos causas que lerama a parmanecer ma menaridade Senda assim a hamem é Q própro responsáriel pela sur ños esclorecimento.

Muitas das pessoas twaye em dis sás insop nzes de bazer jul. gamentas merals porque simplesmente cumprom ondens sum questisnar.

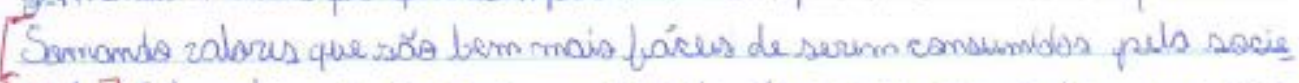

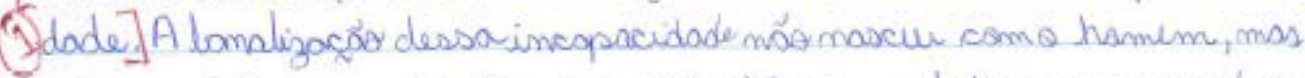

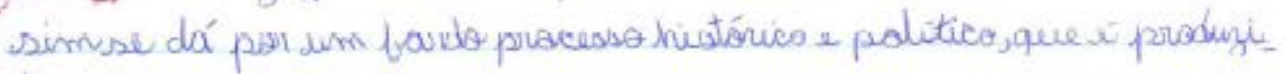
do pelos práprias seres the momos

A rialencis se toma táa lavial pais já passau a fazer parte do mooss dia a dia, no quel nem nos surpreen demas mais. (1) mal camecca a se tarnar banal ma mamento em que a livarnemu mö́ exerce a felasolica, que é pensar. Senda muits mais frície a lanslidade da imal ve instalar em un vasio de pensamentas.

Trabalho 2: 
Banalidade do Mal, Esclarescimento e Filosofia

(1) cenceito de Banolidade de Mal criado por Hannah Arendt e abordade em Gein. livro chamade "Eichmann em jerbsailem", frata sobve a hojeno" nificastäo do pensamente crítice e em decorrência disse a sociedade cumpre ordens sem questionar.

10 concerte de esclarecimento segundo Immar nuel Kont, é a saída do individuo da menorida de, é fozer usufruto de seu próprie entendimento sem ser ditado por terooiros.

A filosocia é urra ciência que busca e saber em quastóes humunas, por meio do pensamente a.rolítice.

Pademos perceber que os dois concoitos seño white servelhantes, porén mostram diferenter face. tas de un mesmo problema. Enquanto a Banalidade do Mal apresenta a questäe, o Esclowecimento apro Senta a Solucão desse mal. Enquanto a filosofia éal go muito mais amplo, que tem relagĩo com o penson Us dois conceitos está incorporados na filoso fia, o pensar é o ponto em commm entre eles, como eles abordam isso é diferenciado, OS dois autores partiram de mesmo pontio low problemal Portanto ew poderia afirmar que a solutão do male de outvos proble mas (precunceitos, discursos de odio entre outras coisas praticadas por pes. sous ignorantes) seria o esila recimonto ow Saida da monoridade. Wem empe nö ignolañes e

Trabalho 3: 


\section{0 que is plosstia?}

Acrocity gie u base fundenental paes umo is

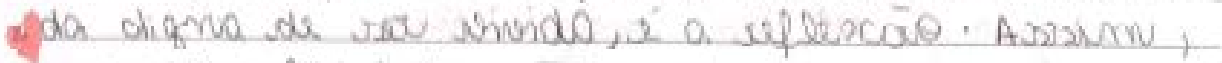

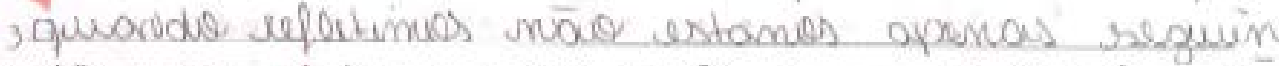

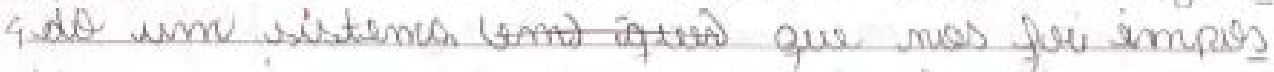

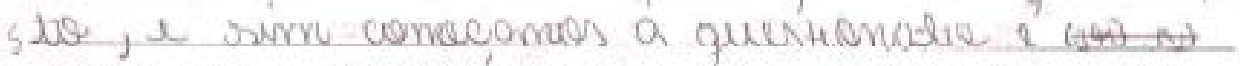

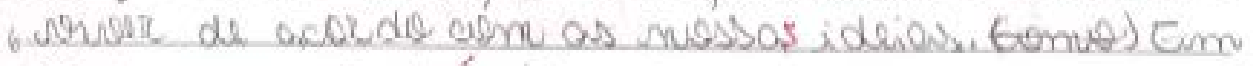

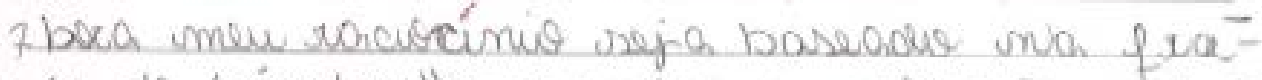

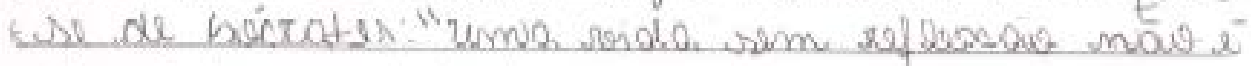

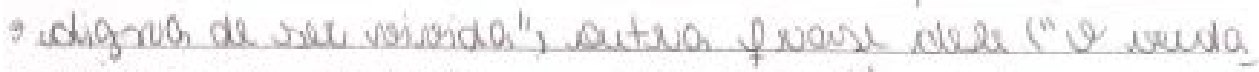

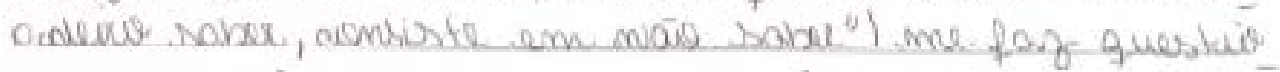

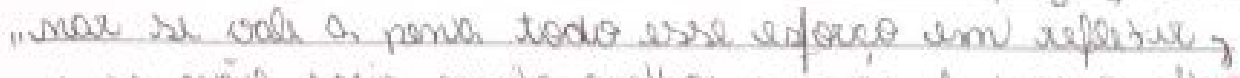

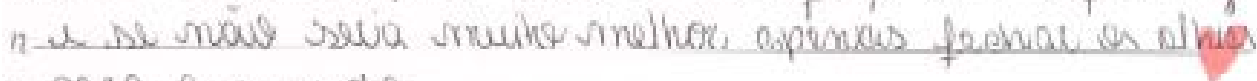
13 peed se mundo.

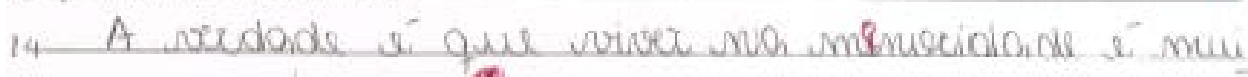

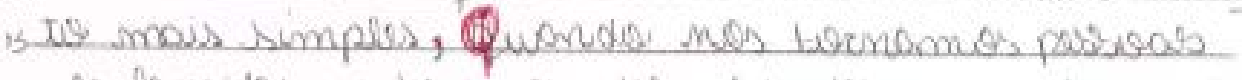

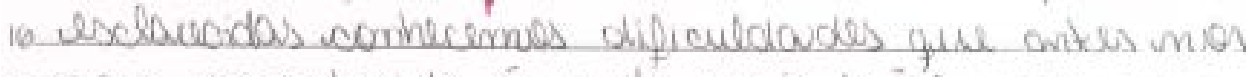

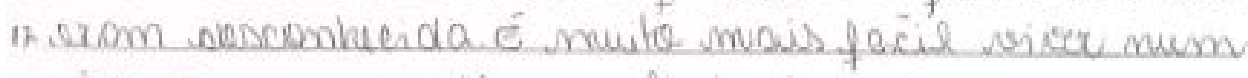

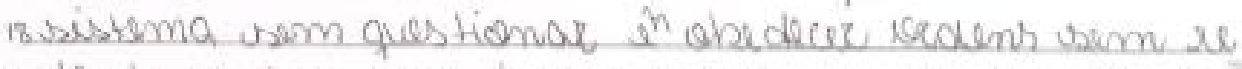

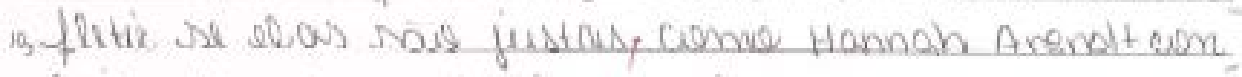

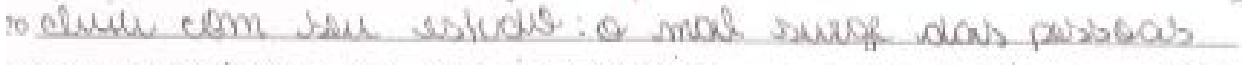

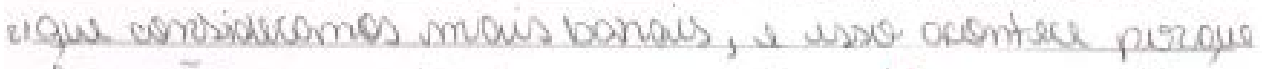

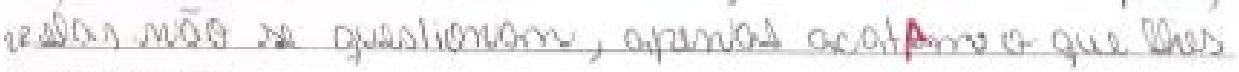
3umandown.

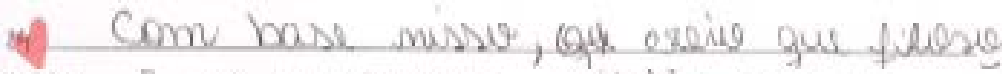
ispia i ise questionar, repletir, perrsar

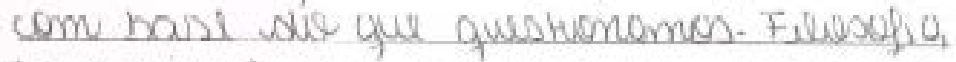
bi o, bases tom chmo sew plimaipal pilar a sequacion.

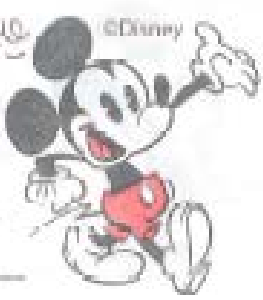

Trabalho 4: 


\section{O que i filosefia?}

A filosofia easte há muito tempo, na verdade, ela sempre rastivi. A filosefia sempre esteve relacionoda ao convivio social e a sabedorva do ser humano. Para entende la, é necessário estudar, etoservar culturas, ideo. logias, questioses éticas, opseniões, linguagens $e$ relligües.

Exastem dois termos que podem ser consede rndion ciontrórios a filosofia: menoridode e bana lidode do mal. Individuos que näa entendem a importância el relevância do pensamento e 1) uñ̃ö as querem entender estão preses em uma menoridade. Merroridade pode ser descrita como a incopacidode de pensar sozinho, não por fulta de entendimento mas sen coragem.

Banalidade do mal é parecido, mas com consciêricia do mal que está pruaticando, o indivéduo nāo mecessoriamenté concorda, mas ciontenus com as atos por estar simplesmente seguendo regres, unesmo que essuspossamultrapassar os direitos humanos. um belo eccemplo de que a unnorância humana pode ferir. Gomo deferidia Sécrates, "uma vida sem ueflexăo não i digna de ser vivida." Ser eqnorante fa 'é um erro, não buscar refletir e mudar, é o pur deles. Filosofia é entäo, $\theta$ prazer de pensar selore a. rida e 19 mundo.

\section{CONSIDERAÇÕES FINAIS}

O objetivo de motivar a discussão em sala de aula sobre os conceitos de banalidade do mal, autonomia e esclarecimento, foi instigar os (as) estudantes das turmas de primeiro ano do ensino médio do CAP/UFRGS a reflexão sobre as possíveis consequências desumanas e imorais de ações e escolhas irrefletidas. Nesse sentido, procurei oportunizar o contato dos (as) estudantes com textos clássicos da história da Filosofia, tendo como propósito fomentar a crítica qualificada e suas capacidades de reconhecimento de um trágico e perigoso paralelo entre contextos históricos do passado e de nossos dias.

As consequências da tolerância irrestrita a discursos nitidamente fascistas, cujos alvos são as parcelas da população brasileira historicamente marginalizadas, tem ganhado força e legitimidade institucional dentro de setores da sociedade brasileira que antes jamais poderíamos imagi- 
nar8. Mais do que isso, o próprio Estado que deveria zelar e combater tais posturas, muitas vezes é perpetrador de ações fundamentadas em tais discursos e/ou serve de guarida para essas posturas. Por esses motivos, entendo que a apresentação da Filosofia às turmas de primeiro ano do ensino médio do CAP/UFRGS (tendo como intuito o fomento da reflexão, do estudo e da análise sobre as diferentes contribuições engendradas por pensadores e pensadoras ao longo da história, bem como sobre situações e contextos semelhantes a atual conjuntura política e social vivida no Brasil) revelou-se muito bem-sucedida na medida em que se pôde observar: a qualificada apropriação dos conceitos pelos (as) estudantes; o desenvolvimento de suas capacidades analítico-comparativas; o estabelecimento de relações entre diferentes temáticas e contextos e a elaboração de argumentos originais sobre as temáticas debatidas em sala aula. Assim, acredito que esse módulo introdutório caracterizou fielmente a Filosofia como uma atividade reflexiva autônoma, avessa a posturas fundamentadas em preconceitos, má fé, e ao todo tipo de autoritarismo. Por fim, creio ter atingido os objetivos inicialmente estabelecidos e, além disso, ter demonstrado aos (as) estudantes a importância do exercício filosófico para a melhor compreensão da nossa realidade.

\section{REFERÊNCIAS:}

ARENDT, Hannah. Eichmann em Jerusalém: um relato obre a banalidade do mal. São Paulo: Companhia das Letras, 1999.

DEUTSCHE WELLE. Mídias sociais favorecem a imbecilidade. Disponível em: https://www.dw.com/ $\mathrm{pt-br/m \% C3 \% ADdias-sociais-favoreceram-a-imbecilidade/a-41567902.} \mathrm{Acesso} \mathrm{em:} 25$ de março de 2019.

DIAS, Thiago. Pode Hannah Arendt explicar o bolsonarismo? Disponível em:

https:// outraspalavras.net/outrasmidias/bolsonaro-arendt-e-a-ignorancia-esmagadora-dos-indiferentes/?fbclid=IWAR 1 KREIPhyicve0n 1 EpMFMzd2RSD5dGnejnsqaY-15XUJ3CN13CWEEsjIXU\%20. Acesso em: 04 de abril de 2019.

ECO, Umberto. O fascismo eterno. Tradução de Eliana Aguiar. Rio de Janeiro: Record. 2008.

EXPERIMENTER: The Stanley Milgram Story. Direção de Michael Almereyda. British Board of Film Classification, 2015. 1 filme (98 min.), sonoro, legenda, colorido.

REVISTA FÓRUM. ECo: redes sociais deram voz a legião de imbecis. Disponível em: https://www. revistaforum.com.br/eco-redes-sociais-deram-voz-a-legiao-de-imbecis/. Acesso em 11 de abril de 2018.

KANT, Immanuel. O que é esclarecimento? In: Resposta à pergunta: o que é esclarecimento? Tradução de Paulo Cesar Gil Ferreira. Rio de Janeiro: Viaverita, 2011.

MORAES, Eduardo Carli de. "A banalidade do mal e sua tenebrosa atualidade: reflexões na companhia de Hannah Arendt, Zygmunt Bauman, Stanley Milgram, G. Agambem, Márcia Tiburi, entre outros". A casa de vidro. Disponível em: https://acasadevidro.com/2018/02/22/

8 Supremo Tribunal Federal (STF) absolve o candidato a presidência Jair Bolsonaro (PSL/RJ) da acusação de racismo (Disponível em: < http://www.stf.jus.br/portal/cms/verNoticiaDetalhe.asp?idConteudo=389384 > Acesso em: 23 de setembro de 2018). 
estudos-filosoficos-a-banalidade-do-mal-e-sua-tenebrosa-atualidade-reflexoes-na-companhiade-hannah-arendt-stanley-milgram/. Acesso em 12 de abril de 2018.

PLATÃO. Apologia de Sócrates. Tradução de José Trindade Santos. Imprensa Nacional - Casa da Moeda: Lisboa, 1983.

PLATÃO. Teeteto. Trad. de Carlos Alberto Nunes. Belém: Editora Universitária. 2001.

SOUKI, Nádia. "Três momentos do conceito de mal em Hannah Arendt". In: SCHIV, Sônia Maria; KUSKOSKI, Matheus Soares (orgs.). Hannah Arendt: pluralidade, mundo e política. Porto Alegre: Observatório gráfico, 2013.

SOUZA, Jessé. A elite do atraso. Rio de Janeiro: Estação Brasil, 2019.

SPINELLI, Miguel. Ética e política: a edificação do éthos cívico na paideia grega. São Paulo: Loyola. 2017. 